\title{
Growth and Characterization of Novel System of Nanoparticles Embedded in Phosphate Glass Matrix
}

\author{
Wageh Swelm ${ }^{1}$, Anwar Higazy ${ }^{2}$, Mohammed Algradee ${ }^{2,3}$ \\ ${ }^{1}$ Physics and Engineering Mathematics Department, Faculty of Electronic Engineering, Menufiya University, Menouf, Egypt; \\ ${ }^{2}$ Department of Physics, Faculty of Science, Menoufia University, Shebin El-Koom, Egypt; ${ }^{3}$ Department of Physics, Faculty of \\ Science, Ibb University, Ibb, Yemen. \\ Email: wageh1@yahoo.com
}

Received March $7^{\text {th }}, 2011$; revised March 22 ${ }^{\text {nd }}, 2011$; accepted March 25 ${ }^{\text {th }}, 2011$.

\begin{abstract}
We present a study of growth of a novel system of CdTe nanoparticles embedded in sodium/lithium-mixed phosphate glass matrix in a strong quantum confinement regime. The prepared systems are characterized by differential thermal analysis, X-ray diffraction, TEM, optical absorption, infrared and Raman Spectroscopy. We have investigated the effect of glass matrix composition and annealing time on the growth mechanism of the CdTe semiconductor nanoparticles. We found that the decrease in $\mathrm{Na}_{2} \mathrm{O}$ content and addition of $\mathrm{ZnO}$ to the glass composition is strongly affecting the nanoparticles formation and capping surface of the nanoparticls. On the other hand, we have calculated the size of nanoparticles by effective mass approximation (EMA) and empirical method based on tight binding approximation and found that the calculation based on tight binding approximation are very plausible than that one calculated by EMA.
\end{abstract}

Keywords: Semiconductor Nanoparticles, CdTe, Infrared and optical Spectroscopy

\section{Introduction}

Semiconductor nanoparticles have received considerable attention in the field of material science research due to their unique optical and electronic properties. These unique properties like the enhancement in the luminescence properties of semiconductor nanoparticles, with high spectral purity and excellent fluorescence efficiencies. Another advantage comes from the size-tunability of their emission and absorption. The colour of absorption and emission can be tuned just by changing the size of the nanocrystals, without any changes in composition or stoichiometry. These properties make nanoparticles a very attractive material for many applications.

The unique in optical properties of the nanoparticles comes from the quantum confinement effects which arise when the size of the semiconductor have dimensions of 10 nanometers or less [1-3]. In this framework a number of researches have been dedicated to the fabrication of small semiconductor nanocrystals in different type of dielectric matrices either solids or liquids [4-8].

Specifically, II-VI semiconductor nanoparticles have attracted much attention due to both their unique proper- ties brought by the three dimensional quantum confinements and their potential for photonic applications as optical devices [9-11]. CdTe is one of the II-VI semiconductor nanocrystals which have a large exciton Bohr diameter $\sim 15 \mathrm{~nm}$, and therefore it offers the possibility of studying quantum confinement effects in higher cluster size regimes. Up to now very rare work are published about the glass matrices doped with CdTe nanocrystals [12-18].

Therefore, it is desired to develop new glasses with semiconducting nanocrystals of will controlled size, size distribution and content, which may extended the application of these composite to the new era of optical function devices. In view of this, we have prepared a novel system of nanoparticles embedded in glass. To the best of our knowledge, CdTe nanocrystal embedded in sodium/lithium-mixed phosphate glass matrix has not been reported yet. Our nanoparticles doped sodium/lithiummixed phosphate glass matrix begun in 2008 [19] and 2009 [20], and we have studied the growth of CdSe and PbSe nanocrystals in this glass matrix through optical absorption, X-ray diffraction and infrared spectroscopy 
techniques. In this work, it is intended to study the growth of CdTe quantum dots in $\mathrm{P}_{2} \mathrm{O}_{5}-\mathrm{Na}_{2} \mathrm{O}-\mathrm{Li}_{2} \mathrm{O}$ and $\mathrm{P}_{2} \mathrm{O}_{5}-\mathrm{Na}_{2} \mathrm{O}-\mathrm{ZnO}-\mathrm{Li}_{2} \mathrm{O}$ glass matrices. We have studied the effect of glass composition and annealing time on the growth of nanoparticles. The prepared samples characterized by differential thermal analysis, X-ray diffraction, TEM, optical absorption spectroscopy, Infrared spectroscopy and Raman Spectroscopy.

\section{Preparation}

In this work we have prepared a new system of CdTe nanoparticles embedded in phosphate glass matrix. There are some problems for the preparation of nanoparticles embedded in glass. Among these problems the low solubility of semiconductor in the melted glass matrix which lead to low concentration of the nanoparticles in the glass matrix. The melting point of the glass also is very important for reducing the loss of semiconductor elements. As the melting point is dependent on the component of glass matrices so the choices of these elements are very important. To avoid these problems we have chosen a glass matrix with melting temperature $\sim 1100^{\circ} \mathrm{C}$, which is less than about $500^{\circ} \mathrm{C}$ in analogies with silicate glass matrices. We have prepared two systems with different compositions of glass matrix. These two systems are $\mathrm{P}_{2} \mathrm{O}_{5}-\mathrm{Na}_{2} \mathrm{O}-\mathrm{Li}_{2} \mathrm{O}-2 \mathrm{wt} \% \mathrm{CdO}-2 \mathrm{wt} \% \mathrm{Te}$ and $\mathrm{P}_{2} \mathrm{O}_{5}-\mathrm{Na}_{2} \mathrm{O}-$ $\mathrm{ZnO}-\mathrm{Li}_{2} \mathrm{O}-2 \mathrm{wt} \% \mathrm{CdO}-2 \mathrm{wt} \% \mathrm{Te}$. On the preparation of the second system $\mathrm{P}_{2} \mathrm{O}_{5}-\mathrm{Na}_{2} \mathrm{O}-\mathrm{ZnO}-\mathrm{Li}_{2} \mathrm{O}-2 \mathrm{wt} \% \mathrm{CdO}$ -2wt\%Te, we have added $7 \%$ of $\mathrm{ZnO}$ on the expense of $\mathrm{Na}_{2} \mathrm{O}$. We have calculated the amounts of consisting components $\left(\mathrm{P}_{2} \mathrm{O}_{5}, \mathrm{Na}_{2} \mathrm{O}, \mathrm{ZnO}\right.$ and $\left.\mathrm{Li}_{2} \mathrm{O}\right)$ using the molecular formula of glass. Hereafter, we call the two systems $\mathrm{P}_{2} \mathrm{O}_{5}-\mathrm{Na}_{2} \mathrm{O}-\mathrm{Li}_{2} \mathrm{O}-2 \mathrm{wt} \% \mathrm{CdO}-2 \mathrm{wt} \% \mathrm{Te}$ and $\mathrm{P}_{2} \mathrm{O}_{5}-$ $\mathrm{Na}_{2} \mathrm{O}-\mathrm{ZnO}-\mathrm{Li}_{2} \mathrm{O}-2 \mathrm{wt} \% \mathrm{CdO}-2 \mathrm{wt} \% \mathrm{Te}$ as $\mathrm{S} 1$ and $\mathrm{S} 2$, respectively. The raw materials used in preparation are $\mathrm{Li}_{2} \mathrm{CO}_{3}, \mathrm{Na}_{2} \mathrm{CO}_{3}, \mathrm{ZnO}, \mathrm{P}_{2} \mathrm{O}_{5}, \mathrm{CdO}$ and Te reagent grades. The raw materials were weighted, mixed and stirred mechanically many times to obtain homogeneous mixture. The mixture has put in porcelain crucibles and inserted in an electric furnace held at $250^{\circ} \mathrm{C}$ for $1 \mathrm{~h}$. This process of heat treatment allows the $\mathrm{P}_{2} \mathrm{O}_{5}$ decompose and react with other raw materials before melting. Then the mixtures have transferred to a second furnace which held at $1100^{\circ} \mathrm{C}$ for $15 \mathrm{~min}$ for melting (the melting temperature is depending on the composition of the base glass). Then the melt has poured into two mild steel split mould previously heated to $210^{\circ} \mathrm{C}$. Then the samples immediately transferred to an annealing furnace held at $210^{\circ} \mathrm{C}$, only for $1 \mathrm{~min}$ then the composite was allowed to cool gradually to room temperature to relieve excess internal stress in the glass base and to initiate the nucleation and growth of the nanoparticles. This adopted method allows pro- ducing samples with small nanoparticles and narrow size distribution embedded in the glass matrix, hereafter we call these samples as quenched.

In view of a study of thermal annealing of our samples, we have also performed a prior analysis of the composite versus temperature. A deferential thermal analysis measurement (DTA) for as quenched S2 sample is shown in Figure 1. DTA allow us to identify the glass transition temperature $\left(T_{\mathrm{g}}\right)$, onset crystallization temperature $\left(T_{\mathrm{x}}\right)$ and crystallization peak temperature $\left(T_{\mathrm{p}}\right)$. We have found the values of $T_{\mathrm{g}}, T_{\mathrm{x}}$, and $T_{\mathrm{p}}$ are 270,499 and $511^{\circ} \mathrm{C}$, respectively. According to these result we have treated the produced samples at $350^{\circ} \mathrm{C}$ for different time periods to grow different size of nanoparticles. The samples have been kept in desiccator to prevent possible attack by moisture. Some samples were polished to optical quality for optical measurements. For this purpose, ethylenglycole have been used to avoid the selective removal of any components from the surface layer.

\section{Characterization}

The obtained composites were characterized by different techniques. Thermal properties were studied using Shimadzu DTA-50 in a platinum crucible and nitrogen flux with flow rate of $10 \mathrm{ml} / \mathrm{min}^{-1}$ to determine glass transition temperature, $\left(T_{\mathrm{g}}\right)$, crystallization onset temperature, $\left(T_{\mathrm{x}}\right)$, and crystallization peak temperature, $\left(T_{\mathrm{p}}\right)$. The $\mathrm{X}$-ray analysis was performed on a Philips Pw1373 $\mathrm{X}$-ray diffractometer with $\mathrm{Cu}$ radiation $\left(\lambda=1.542{ }^{\circ} \mathrm{A}\right)$ and $\mathrm{Ni}$ filter operated at $36 \mathrm{kV}$ and $20 \mathrm{~mA}$ with a scanning rate of $2 \mathrm{deg} \mathrm{min}^{-1}$ in the angular range 20 to $70^{\circ}$. The optical absorption spectra were recorded using a UV-VIS spectrophotometer (Unico UV-VIS double beam model 4862, USA) in the spectral range 200 - 1000 $\mathrm{nm}$ at room temperature. The morphology of the samples and particle distribution were characterized by JEOL



Figure 1. DTA curve of the as quenched S2 sample. The large difference between the onset crystallization temperature and glass transition $\left(241^{\circ} \mathrm{C}\right)$ will be promise for further annealing attempts as future work. 
JEM 1230 transmission electron microscopy (TEM) operated at $200 \mathrm{kV}$ accelerating voltage. The samples were prepared by making a suspension from the glass powder in Ethylene Glycol. The suspension was centrifuged to collimate the large size particles. Then a drop of the suspension was put into the copper grid (400 mesh) in each solution of nanoparticles. The IR transmission spectra of the glass samples were measured for each glass sample over the range, $4000-400 \mathrm{~cm}^{-1}$ of wave numbers. A JASCO 460 FTIR (made in Japan) Infrared Spectrometer was used in conjunction with the potassium bromide, $\mathrm{KBr}$, disc technique. For this, powdered glass samples were thoroughly mixed with dry $\mathrm{KBr}$ in the ratio 1:20 by weight and the pellets were formed using a pellet press. Raman scattering spectra were recorded at room temperature using a Jasco FT/IR 6300-RFT and Raman Attachment with a single monochromator and a filter. The excitation was provided by Nd: YVO4 laser at $1064 \mathrm{~nm}$ (power $200 \mathrm{~mW}$ ). All measurements were carried out on bulk vitreous samples at room temperature.

\section{Results and Discussions}

We have investigated the effect of adding $\mathrm{ZnO}$ to the components of glass matrix on the structure configuration through density calculation. Density is affected by structural softening/compactness, changes in geometrical configuration, coordination number, cross-link density and the dimensions of interstitial spaces in the structure. We have determined the density $\rho$ of S1 and S2 composites using Archimedes method, in this method toluene is used as an immersion liquid. The density calculated according to the following equation:

$$
\rho=\rho_{t}\left(W_{a}-W_{a 1}\right) /\left[\left(W_{a}-W_{t}\right)+\left(W_{t 1}-W_{a 1}\right)\right]
$$

where, $\rho_{t}$ is the density of toluene and equal 0.653 $\mathrm{gm} / \mathrm{cm}^{3}$ at $20^{\circ} \mathrm{C}, W_{a}$ is the weight of the glass in air, $W_{t}$ is the weight of the glass in toluene and $W_{a 1}, W_{t 1}$ are weights of suspended thread in air and toluene, respectively. Repeated density measurements were agreed within $\pm 0.01 \%$. The calculated density for S1 and S2 samples are 2.49 and $2.58 \mathrm{gm} / \mathrm{cm}^{3}$, respectively. We have attributed the increase in the density of S2 composite contain $\mathrm{ZnO}$ to the difference in molecular weight between $\mathrm{Na}_{2} \mathrm{O}$ (61.98) and $\mathrm{ZnO}$ (81.38), i.e., introducing heavier molecule into the structure of glass instead of lighter one increase the density.

To completely explain the difference in density for the two composities S1 and S2, we have calculated the molar volume, $V_{m}$, of each composite using: $V_{m}=M / \rho$, where, $\mathrm{M}$ is the molecular weight of glass components.

The calculated molar volume of S1 and S2 composites are 42.35 and $41.41 \mathrm{~cm}^{3}$, respectively. This result can be explained that the addition of $\mathrm{ZnO}$ to $\mathrm{P}_{2} \mathrm{O}_{5}$ glass in the expense of $\mathrm{Na}_{2} \mathrm{O}$ can increase the cross-links between phosphate chains [21]. As alkali ions $\left(\mathrm{Li}^{+}, \mathrm{Na}^{+}\right)$can lead to the breaking of P-O-P linkages and the creation of non-bridging oxygen atoms in the glass [22], then, adding zinc oxide in the expense of $\mathrm{Na}_{2} \mathrm{O}$ or $\mathrm{Li}_{2} \mathrm{O}$ can increase the cross-links between phosphate chains and can reduce the number non-bridging oxygen. The decrease of non-bridging oxygen bonds may be lead to a decrease in the probability of formation of Te-O bond at the surface of the nanoparticles.

Figure 2 shows the X-ray diffraction pattern (XRD) for as quenched S1 sample. The XRD pattern shows a diffraction lines at $2 \theta=23.58^{\circ}, 25.78^{\circ}, 29.75^{\circ}, 35.41^{\circ}$, $41.033^{\circ}, 45.53^{\circ}, 50.27^{\circ}, 52.93^{\circ}, 56.95^{\circ}, 59.88^{\circ}$ and $61.33^{\circ}$ corresponding to (100), (101), (102), (103), (110), (112), (015), (022), (023), (106) and (204) planes of Hexagonal CdTe, respectively (JCPDS data file: 80-0089-Hexagonal). Besides the planes of the Hexagonal CdTe there are some diffraction peaks at $31.2^{\circ}, 38.79^{\circ}$ and $44.26^{\circ}$ which corresponding $\mathrm{TeO}_{2}$ at the surface of the nanoparticles (JCPDS data file: 74-1131). This result indicates that our quenching method leads to formation and crystallization of CdTe nanoparticles which covered by Te-O bonds at the surface of the nanoparticles.

Figure 3 presents the XRD of as quenched S2 sample; here we have added $7 \% \mathrm{ZnO}$ on the expense of $\mathrm{Na}_{2} \mathrm{O}$. The XRD pattern shows a diffraction lines at $2 \theta=23.58^{\circ}$, $25.0^{\circ}, 26.15^{\circ}, 30.66^{\circ}, 35.41^{\circ}, 39.40^{\circ}, 41.94^{\circ}, 48.8^{\circ}, 52.56^{\circ}$, and $59.51^{\circ}$ corresponding to(100), (101), (003), (102), (103), (220) C, (110), (200), (022) and (106) planes of Hexagonal CdTe (JCPDS data file: 80-0089- Hexagonal) and the peak appeared at $39.40^{\circ}$ corresponding to (220) cubic phase. In addition to, the diffraction lines appeared at $2 \theta=31.75^{\circ}$ and $37.37^{\circ}$ which related to $\mathrm{TeO}_{2}$ at the surface of the nanoparticles. Clearly, there is a remarkable difference between the two diffraction patterns of S1 and S2 glass composite. The most important change is highly increasing in the intensity of the peak at $2 \theta=23.58^{\circ}$ which corresponding to (100) plane. In addition, the

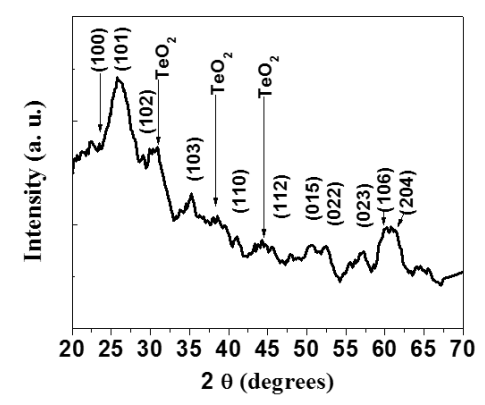

Figure 2. X-ray diffraction pattern of as quenched S1 sample. The CdTe nanoparticles embedded in glass have Hexagonal structure and the diameter of the nanoparticles is $2.04 \mathrm{~nm}$ as calculated by Debye-Sherrer equation. 


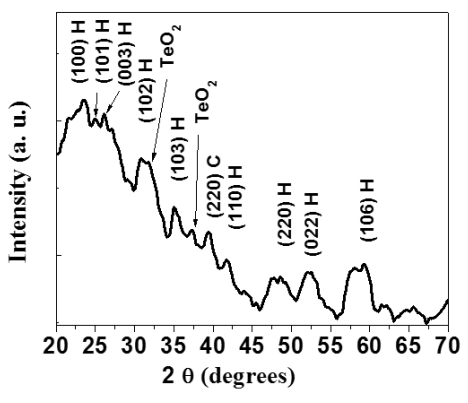

Figure 3. X-ray diffraction pattern of as quenched S2 sample. The CdTe nanoparticles embedded in glass have Hexagonal structure and the diameter of the nanoparticles is $2.76 \mathrm{~nm}$ as calculated by Deby-Sherrer equation.

relative intensity of $\mathrm{TeO}_{2}$ to (100) line is decreased for S2 sample. These result revealed that the decrease in $\mathrm{Na}_{2} \mathrm{O}$ content and addition of $\mathrm{ZnO}$ to the glass composition is strongly affecting the nanoparticles formation and capping surface of the nanoparticls which confirmed by the result of molar volume calculation.

We have calculated the mean sizes for the nanoparticles embedded in glass for as quenched S1 and S2 samples using the (101) and (100) reflections, respectively. The half width of these two peaks has been used to calculate size of CdTe nanoparticles using Debye-Sherrer equation [23],

$$
L=\frac{0.94 \lambda}{B \cos \theta}
$$

$L$ is the coherence length, $B$ is the full width at half maximum of the peak, $\lambda$ is the wavelength of X-ray radiation, and $\theta$ is the angle of diffraction. In case of a small crystallites $L=3 / 4 \mathrm{~d}$, where $\mathrm{d}$ is diameter of nanoparticles. The calculated nanoparticles diameters for the as quenched S1and S2 samples are 2.04 and $2.76 \mathrm{~nm}$, respectively.

Figure 4(a) and (b) shows TEM images for the as quenched S1 and S2 samples. Obviously, we can see the glass matrix contains crystalline CdTe particles dispersed and well separated in the glass matrix. The figures reveals that mean size of the nanoparticles are 3.22 and 3.6 $\mathrm{nm}$ for S1 and S2, respectively.

Cadmium telluride have relatively large Bohr radius of approximately $7.5 \mathrm{~nm}$ which is three times the diameter of the nanoparticles, consequently the prepared nanoparticles in strong confinement regime. We have used the optical absorption spectroscopy to analyze the influence of heat treatment duration and change in glass composition on the light absorption mechanisms in CdTe nanoparticles embedded in glass. From the position of the first absorption maximum and the fundamental absorption edge we have obtained some information on the growing of the nanoparticles and deduced some important proper- ties of the material, like the optical band gap, and size of the nanoparticles. All the absorption spectra applied at room temperatures for all samples.

Figure 5 shows the comparison between the absorption spectra for the as quenched S1 and S2 samples. The absorption spectra for S1 sample show an initial step at $2.42 \mathrm{eV}$. This unresolved peak at $2.42 \mathrm{eV}$ is blue shifted by $0.99 \mathrm{eV}$ from the bulk band gap of CdTe. While the absorption spectra for the as quenched S2 sample is clearly different as shown in Figure 5. A distinct peak appears at $2.34 \mathrm{eV}$ and is blue shifted by 0.91 $\mathrm{eV}$ from the bulk band gap of CdTe. These results indicate a coexistence of nucleation and growth of nanopaticles during the quenching process due to the low rate of cooling around the transition temperature. The difference between the absorption spectra of the S1 and S2 samples means that the size of the nanoparticles formed in glass contains $\mathrm{ZnO}$ is greater than the particles formed in $\mathrm{Zn}$ free glass. These results indicated that the presence of $\mathrm{ZnO}$ in the host glass matrix leads to an increase in the number of CdTe nanoparticles nucleated during the quenching of the melt to room temperatures which confirm the obtained results from X-ray analysis. It's worth mention that there is a difference of the optical band gap of the two bases of glass. The optical band gap for the base glass of S1 and S2 samples are 3.71 and $4.04 \mathrm{eV}$ respectively. This difference of the optical band gap of base glass leads to a change in the degree of confinement of the two composites which in turn affect on the oscillator strength and energy of the absorption spectra. Also, the shift of the absorption maximum for S2 sample to lower energy indicates that the $\mathrm{Zn}$ ions don't replaced the $\mathrm{Cd}$ ions in the core of the nanoparticles, if $\mathrm{Zn}$ replaced Cd will lead to shift of the absorption band to higher energy. We have calculated the sizes of nanoparticles embedded in glass for S1 and S2 samples from the position of the first absorption maximum using effective mass approximation model for spherical particles. In this model the ground electron hole pair state energy $\left(E_{1 s 1 s}\right)$ can be approximately calculated using the expression [1]:

$$
E_{1 s 1 s}=E_{g}+\pi^{2}\left(\frac{a_{B}}{a}\right)^{2} R_{y}^{*}-1.786 \frac{a_{B}}{a} R_{y}^{*}-0.248 R_{y}^{*}
$$

where $E_{1 s 1 s}$ is the energy of the first absorption maximum, $E_{g}$ is the bulk band gap energy, $a$ is the nanoparticle radius, $a_{B}$ is the exciton Bohr radius $\left(a_{B}=7.5 \mathrm{~nm}\right)$, and $R_{y}^{*}$ is the exciton Rydberg energy $\left(R_{y}^{*}=10 \mathrm{meV}\right)$. The nanoparticle diameters (d) calculated using above equation are $4.58 \mathrm{~nm}$ and $4.78 \mathrm{~nm}$ for S1 and S2, respectively. These values are extremely higher than the sizes estimated using Debye-Scherrer equation and measured by TEM. On the other hand, the difference between the sizes 


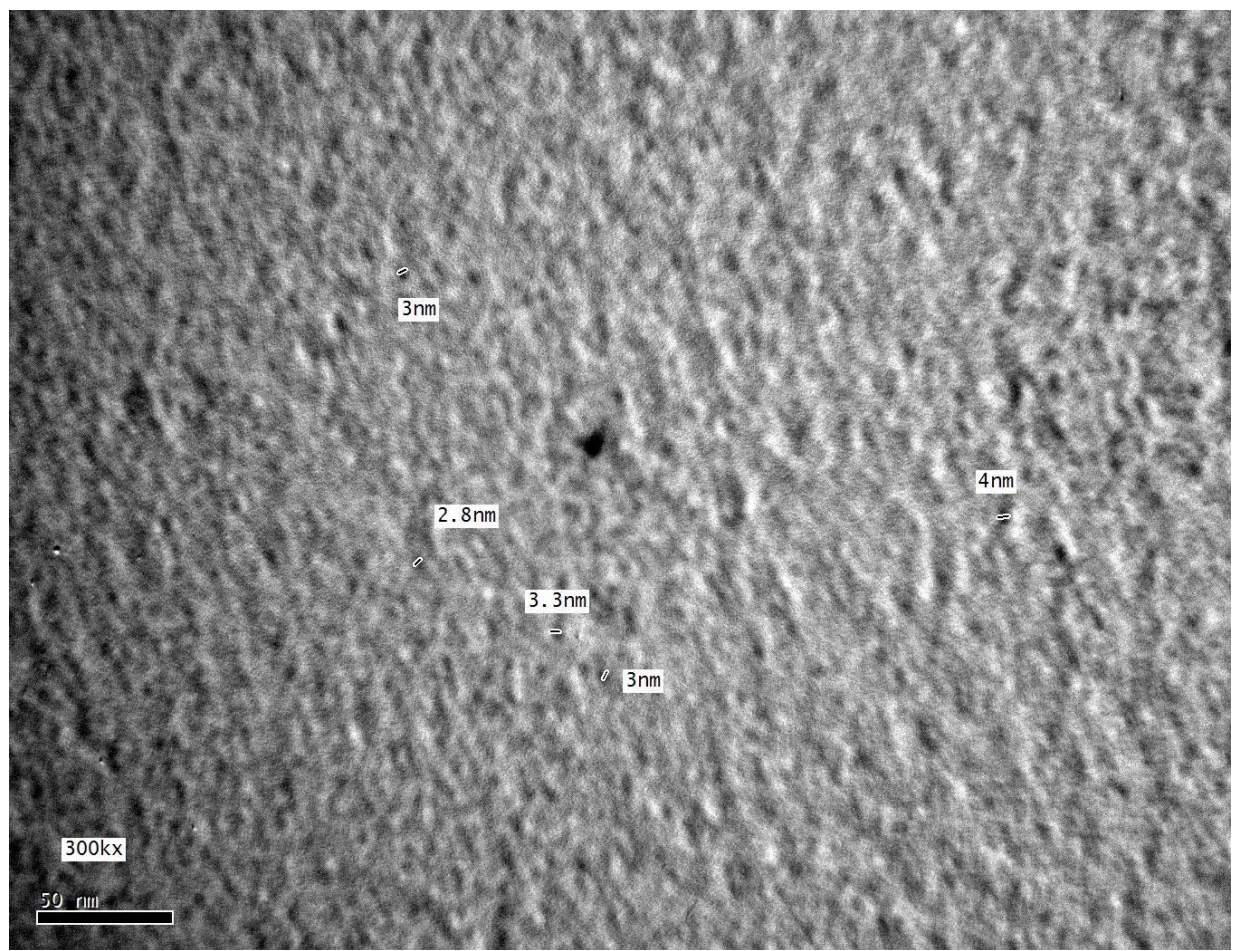

(a)

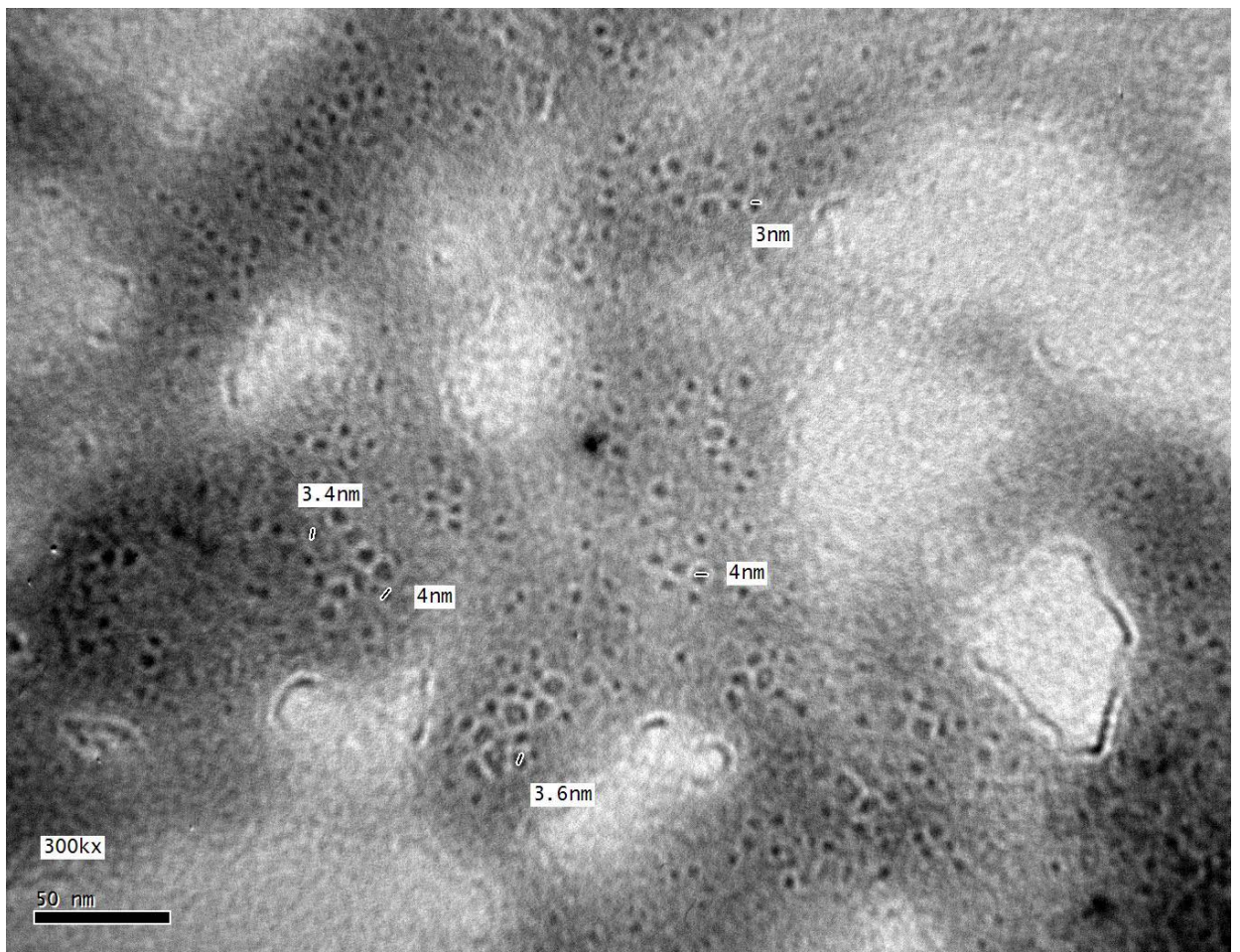

(b)

Figure 4. (a) TEM image for as quenched S1 sample (the mean diameter $~ 3.22 \mathrm{~nm}$ ) and (b) TEM image for as quenched S2 sample (the mean diameter $\sim 3.6 \mathrm{~nm}$ ). 


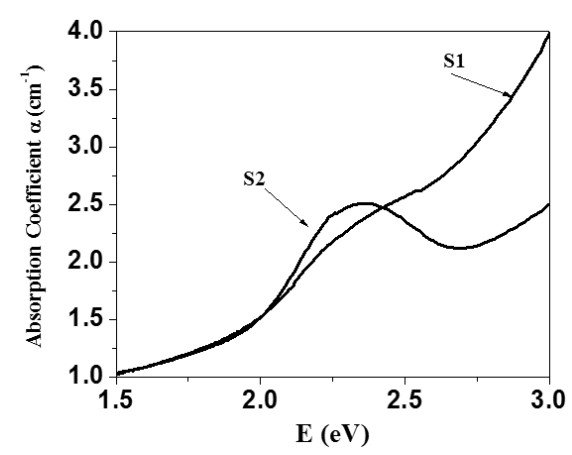

Figure 5. Absorption spectra of as quenched S1 and S2 samples.

of the naoparticles formed in the two matrices is not compatible with the X-ray and TEM results. In addition to, the two bases of glass have different optical band gap. In view of all of these information we can attribute the overestimation obtained from the calculations based on the effective mass approximation due to the uses of infinite barrier potential with vanishing wave functions at the boundary. These results indicate that the value of the potential barrier is the crucial parameter for the effective mass calculation to adapt the real sizes of the nanoparticles embedded in glass matrix. This result compatible with the previously reported theoretical result by Laheld and Einevoll which showed that the application of finite barrier will gave reasonable fits to experimental result [24].

On the other hand, we have calculated the size of nanoparticles by the formula based on tight binding approximation. This formula is [25]

$$
E_{g}(d)=E_{g}(\infty)+\frac{1}{a d^{2}+b d+c}
$$

where $E_{g}(d)$ and $E_{g}(\infty)$ are the band gap for the nanoparticle with diameter $\mathrm{d}$ and the bulk state, respectively. $a, b$ and $c$ are constants which were determined by fitting Equation (4) with experimental data [26], the value of $a$, $b$ and $c$ are $0.137,0.0$ and 0.26 , respectively. The calculated sizes for S1 and S2 are 2.45 and $2.65 \mathrm{~nm}$, respectively. These sizes are lied between the estimated values using Debye-Scherrer equation and that one measured by TEM for S1 sample and very close to the estimated values using Debye-Scherrer equation for S2 sample.

Figure 6 shows the effect of annealing time on the absorption spectra of S1 sample. The absorption spectra for the sample annealed for 30 minutes shows a featureless relatively sharp absorption spectrum. With increasing annealing time the sharpness of the absorption spectra increases which indicates a decrease in size distribution. In addition the energy of the absorption edge shifts to lower energy with increasing annealing time.

Figure 7 shows the effect of annealing time on the



Figure 6. The effect of annealing duration on the absorption for $\mathrm{S} 1$ system at constant annealing temperature $350^{\circ} \mathrm{C}$.

absorption spectra of S2 sample. Clearly, for annealing with short duration the absorption spectra grows with a will defined structure peak at $2.34 \mathrm{eV}$, after one hour the absorption spectra shows a shoulder at $2.3 \mathrm{eV}$. With further increasing of annealing time the absorption spectra consists of steep featureless absorption edge.

Due to the appearance of featureless nonstructural absorption spectra for the annealed samples, we have calculated the size of the nanoparticles from the energy dependence of the absorption coefficient near the band edge. The effective band gap of the CdTe nanoparticles calculated from the energy dependence of the absorption coefficient near the band edge using the following relation [27]

$$
(\alpha \hbar \omega)^{2}=E-E_{g}(d)
$$

where $\alpha$ is the absorption coefficient, $E=\hbar \omega$ is the photon energy and $E_{g}(d)$ is the effective band gap energy of the nanoparticles. Figure 8 shows as an example of the relation between $(\alpha \hbar \omega)^{2}$ as a function of photon energy and the linear fitting to this relation for as quenched S1 samples annealed for (60 min). The value of band gaps $E_{g}(d)$ for the nanoparticles were determined by extrapolating the straight line of the linear fit to the energy axis at $(\alpha \hbar \omega)^{2}=0$. We have used these calculated band gaps to calculate the nanoparticle diameters by applying equation 4 for the two composites S1 and S2 annealed at different times. Figure 9 shows the effect of annealing time on the size of nanoparticles in diameters for S1 and S2 systems. Clearly, the nanoparticle diameter increases with increasing annealing time. In addition to, the rate of increasing the diameter for S2 system is relatively higher than that one for S1 system. This result indicates that the addition of $\mathrm{ZnO}$ on the expense of $\mathrm{Na}_{2} \mathrm{O}$ will affect on the diffusion of the semiconductor ions.

In order to investigate the effects of adding $\mathrm{ZnO}$ to the base glass matrix we have studied IR transmission spectra for as quenched S1 and S2 samples. Figure 10 shows the IR transmission spectra recorded over the range 


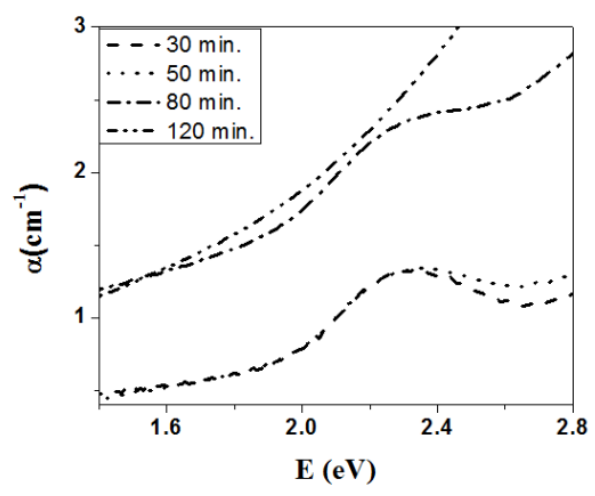

Figure 7. The effect of annealing duration on the absorption spectra for S2 system at constant annealing temperature $350^{\circ} \mathrm{C}$.

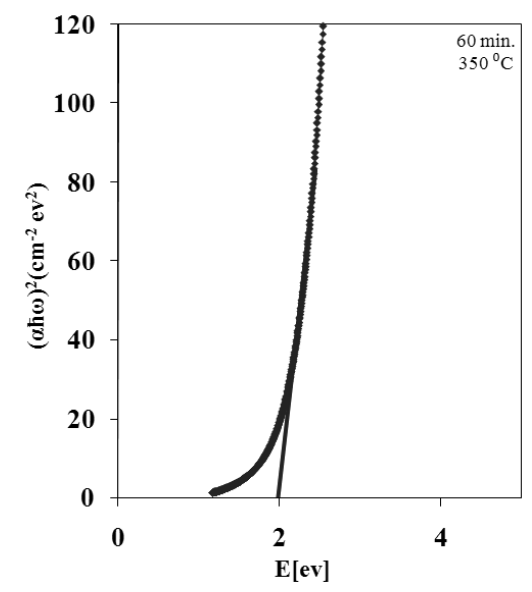

Figure 8. Variation of $(\alpha \hbar \omega)^{2}$ as a function of photon energy and the linear fitting to this relation for as quenched $\mathrm{S} 2$ sample annealed for $60 \mathrm{~min}$ at $350^{\circ} \mathrm{C}$.

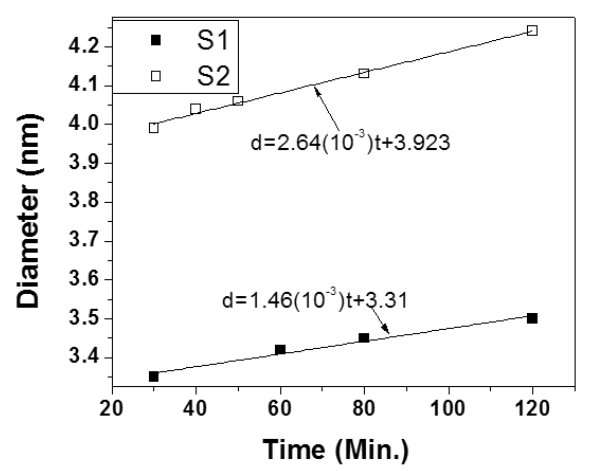

Figure 9. Nanoparticle diameters calculated by Equation (4) which is based on tight binding approximation against the heat treatment time for $\mathrm{S} 1$ and $\mathrm{S} 2$ samples at constant annealing temperature $\left(350^{\circ} \mathrm{C}\right)$. Solid lines and equations show a least-squares fit to the data.

$400-4000 \mathrm{~cm}^{-1}$ for S1 and S2 composities. The features appeared for S1 and S2 samples, can be explained as

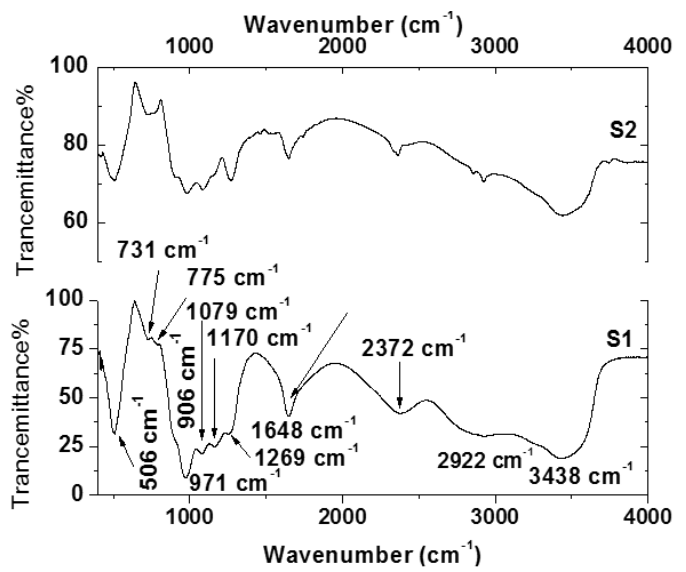

Figure 10. Infrared spectra for as quenched S1 and S2 samples.

follows. The absorption bands around $3438 \mathrm{~cm}^{-1}$ is due to the symmetric stretching of $\mathrm{O}-\mathrm{H}$, and the signal at around $1648 \mathrm{~cm}^{-1}$ is due to the deformation modes of $\mathrm{O}-\mathrm{H}$ groups and absorbed water molecules, $\delta(\mathrm{H}-\mathrm{O}-\mathrm{H})$ [28]. The two bands appeared at 2922 and $2372 \mathrm{~cm}^{-1}$ are related to ethylene glycol which adsorbed on the surface of samples during the smoothing process. The absorption band appeared at $1269 \mathrm{~cm}^{-1}$ corresponding to a $\mathrm{P}=\mathrm{O}$ vibration band [29], the $\mathrm{V}_{\text {as }}\left(\mathrm{PO}_{2}\right)^{-}$asymmetric stretching vibrations at $1170 \mathrm{~cm}^{-1}$ [30], the $v_{a s}\left(\mathrm{PO}_{3}\right)$ asymmetric stretching mode at $1079 \mathrm{~cm}^{-1}$, the $v_{s}\left(\mathrm{PO}_{3}\right)$ symmetric stretching mode at $974 \mathrm{~cm}^{-1}$ [31], the $v_{\text {as }}(\mathrm{P}-\mathrm{O}-\mathrm{P})$ groups at $906 \mathrm{~cm}^{-1}$, the $v_{\mathrm{s}}(\mathrm{P}-\mathrm{O}-\mathrm{P})$ groups at $775 \mathrm{~cm}^{-1}$ and 731 $\mathrm{cm}^{-1}$ [32] and the band at $506 \mathrm{~cm}^{-1}$ due to the deforma-

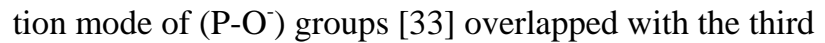
longitudinal optical phonon (3LO) of CdTe. There are some differences between the infrared absorption bands for S1 and S2 samples which reflect some important information about the effect of adding $\mathrm{ZnO}$ to the glass matrix.

1) The position of $\delta(\mathrm{H}-\mathrm{O}-\mathrm{H})$ band is little shifted to lower frequency for S2 sample (i.e., it weakened) which has $\mathrm{ZnO}$ in the base glass matrix. In addition to, the decrease in the intensity of stretching mode of $\mathrm{O}-\mathrm{H}$. These differences reflect that the adding of $\mathrm{ZnO}$ to the glass decrease the hygroscopicity of the composite.

2) The increase in the symmetry on the high energy side of the observed band at $1269 \mathrm{~cm}^{-1}$ which is attributed to $\mathrm{P}=\mathrm{O}$ for $\mathrm{S} 2$ sample. Also the increase in asymetery of $v_{\text {as }}\left(\mathrm{PO}_{2}\right)$-band for S2 sample due to P-O-Zn linkage formation. On the other hand, the absorption band associated with $v_{\text {as }}\left(\mathrm{PO}_{3}\right)$ shifts from $1076 \mathrm{~cm}^{-1}$ for S1 sample to $1087 \mathrm{~cm}^{-1}$ for S2 sample. We attributed these result to the reticulation effect appeared by adding $\mathrm{ZnO}$ to the composite, where Zinc oxide tend to increase the cross-link in the glass matrix and also increase the 
linkage with the surface of the nanoparticles through P-O- Zn-Te bonds.

We have determined the phonon modes using Raman scattering experiments. Figure 11 shows Raman spectrum for S1 and S2 samples. For Zn free glass sample S1 the Raman peaks at 143.14 and $162.14 \mathrm{~cm}^{-1}$ are due to the fundamental transverse optical mode (1TO) and longitudinal optical mode (1LO) of CdTe, respectively [16]. The peak at $120.17 \mathrm{~cm}^{-1}$ corresponds to Te-O bond [34] located at the surface of the nanoparticle. On the other hand, for the sample S2 which contain $\mathrm{Zn}$ in the base glass the vibration due to $1 \mathrm{LO}$ mode and Te-O bond are little shifted to higher energy. This blue shift may be due to lattice contraction or zinc incorporation into the nanoparticle core. Optical absorption spectroscopy showed that there is no incorporation of $\mathrm{Zn}$ into the nanoparticles core. So, we attributed this shift to the lattice contraction. This lattice contraction may be due to local strain in individual crystallites by the increase in density of the S2 base glass and the increase of crystallite size in this matrix. Also its worth to mention that, the relative intensity of the peak due to Te-O bond to $1 \mathrm{LO}$ peak vibration is decreased for the S2 sample, which confirms the obtained result from X-ray analysis. The decrease in intensity of $\mathrm{TeO}_{2}$ vibration mode indicates that the decrease in the number of Te-O bonds at the surface of the nanoparticles. The decrease of number of Te-O bonds may be due to the formation of some Te-Zn-O bonds at the surface of the nanoparticles which is the extension of $\mathrm{P}-\mathrm{O}-\mathrm{Zn}$ in the glass structure.

\section{Conclusion}

We have presented a preparation of a novel system of CdTe embedded in phosphate glass matrix. The prepared samples characterized by differential thermal analysis (DTA), X-ray diffraction, TEM, infrared, Raman and optical absorption spectroscopy. The X-ray diffraction

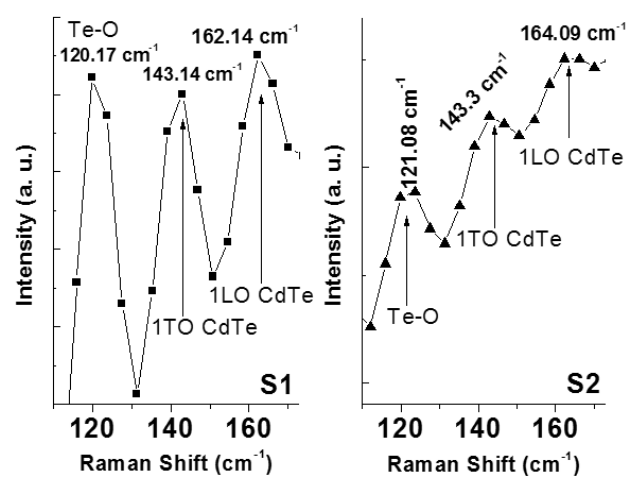

Figure 11. Raman spectra for as quenched S1 and S2 samples. study showed the prepared nanoparticles are crystallized in hexagonal structure and presence of diffraction peak related to $\mathrm{TeO}_{2}$ which cover the surface of the nanoparticles. And Raman spectroscopy showed that a decrease of Te-O bonds at the surface of the nanoparticles embedded in the glass matrix which has $\mathrm{ZnO}$ in the composition of the base glass. On the other hand, we have studied the effect of annealing duration on sizes of the nanoparticles through the optical absorption spectroscopy. We have determined the size of the nanoparticles by XRD and TEM. In addition to, the size of the nanoparticles calculated from the absorption spectra by effective mass approximation and empirical method based on tight binding approximation. These calculations revealed that the sizes of the nanoparticles based on the tight binding approximation are very close to TEM and XRD results.

\section{REFERENCES}

[1] S. V. Gaponenko, “Optical Properties of Semiconductor Nanocrystals,” Cambridge University Press, Cambridge, 1998. doi:10.1017/CBO9780511524141

[2] H. Weller, "Quantized Semiconductor Particles: A Novel State of Matter for Materials Science,” Advanced Materials, Vol. 5, No. 2, February 1993, pp. 88-95. doi:10.1002/adma.19930050204

[3] A. P. Alivisatos, "Semiconductor Clusters, Nanocrystals, and Quantum Dots,” Science, Vol. 271, No. 5251, February 1996, pp. 933-937. doi:10.1126/science.271.5251.933

[4] R. M. Morcos, C. Mitterbaur, N. Browning and S. A. Navrotsky, "Energetics of $\mathrm{CdS}_{\mathrm{x}} \mathrm{Se}_{1-\mathrm{x}}$ Quantum Dots in Borosilicate Glasses,” Journal of Non-Crystalline Solids, Vol. 353, No. 29, September 2007, pp. 2785-2795. doi:10.1016/j.jnoncrysol.2007.05.008

[5] S. Wageh, Z. S. Ling and X. R. Xu, "Growth and Optical Properties of Colloidal ZnS Nanoparticles," Journal of Crystal Growth, Vol. 255, No. 3-4, April 2003, pp. 332337. doi:10.1016/S0022-0248(03)01258-2

[6] S. Wageh, "Raman and Photoluminescence Study of CdSe Nanoparticles Capped with a Bifunctional Molecule,” Physica E, Vol. 39, No. 1, January 2007, pp. 8-14. doi:10.1016/j.physe.2006.12.003

[7] S. Wageh, S. M. Liu and X. R. Xu, "Effect of Aging on CdSe Nanocrystals,” Physica E, Vol. 16, No. 2, 2003, pp. 269- 273. doi:10.1016/S1386-9477(02)00694-X

[8] S. Wageh and M. H. Badr, “ $\mathrm{Cd}_{1-\mathrm{x}} \mathrm{Zn}_{\mathrm{x}} \mathrm{S}$ Nanoparticles Stabilized by a Bifunctional Organic Molecule," Physica E, Vol. 40, No. 8, January 2008, pp. 2810-2813. doi:10.1016/j.physe.2007.12.013

[9] J. Warnock and D. D. Awschalom, “Quantum Size Effects in Simple Colored Glass,” Physical Review B (Condensed Matter), Vol. 32, No. 8, October 1985, pp. 55295531. doi:10.1103/PhysRevB.32.5529

[10] B. G. Potter and J. H. Simmons, "Quantum Size Effects in Optical Properties of CdS-Glass Composites,” Physical 
Review B (Condensed Matter), Vol. 37, No. 18, June 1988, pp. 10838-10845. doi:10.1103/PhysRevB.37.10838

[11] N. F. Borrelli, D. W. Hall, H. J. Holland and D. W. Smith, "Quantum Confinement Effects of Semiconducting Microcrystallites in Glass,” Journal of Applied Physics, Vol. 61, No. 12, June 1987, pp. 5399-5409. doi: $10.1063 / 1.338280$

[12] J. A. M. Neto, L. C. Barbosa, C. I. Cesar, O. L. Alves and F. Galembeck, "Quantum Size Effects on $\mathrm{CdTe}_{\mathrm{x}} \mathrm{S}_{1-\mathrm{x}}$ Semiconductor Doped Glass," Applied Physics Letters, Vol. 59, No. 21, November 1991, pp. 2715-2717. doi:10.1063/1.105894

[13] L. C. Barbosa, V. C. S. Reynoso, A. M. De Paula, C. R. M. De Oliveira, O. L. Alves, A. F. Craievich, R. E. Marottia, C. H. B. Cruz and C. L. Cesar, "CdTe Quantum Dots by Melt Heat Treatment in Borosilicate Glasses," Journal of Non-Crystal Solids, Vol. 219, October 1997, pp. 205-211. doi:10.1016/S0022-3093(97)00330-X

[14] M. H. Yukselici and C. Allahverdi, "Solid-Phase Precipitation of CdTe Nanoparticles in Glass," Physica Status Solidi (B), Vol. 236, No. 3, March 2003, pp. 694-701. doi:10.1002/pssb.200301560

[15] A. A. Lipovskii, E. V. Kolobkova and V. D. Petrik, "Formation of II-VI Nanocrystals in a Novel Phosphate Glass,” Journal of Crystal Growth, Vol. 184-185, No. 1-2, 1998, pp. 365-369. doi:10.1016/S0022-0248(98)80077-8

[16] A. M. De Paula, L. C. Barbosa, C. H. B. Cruz, O. L. Alves, J. A. Sanjurjo and C. L. Cesar, "Size Effects on the Phonon Spectra of Quantum Dots in CdTe Doped Glasses,” Applied Physics Letters, Vol. 69, No. 3, July 1996, pp. 357-359. doi:10.1063/1.118059

[17] S. Wageh, A. A. Higazy, A. H. Khafagy and A. S. Eid, "Synthesis and Characterization of CdTe Nanoparticles embedded in Novel Glass Matrix,” International Journal of Anoscience, Vol. 8, No. 6, December 2009, pp. 605610.

[18] S. Wageh, S. L. Zhao and Z. Xu, “An Optical and Structural Investigation into CdTe Nanocrystals Embedded into the Tellurium Lithium Borophosphate Glass Matrix,” Science in China Series G: Physics, Mechanics and Astronomy, Vol. 53, No. 5, May 2010, pp. 818-822.

[19] S. Wageh, A. S. Eid, S. El-Rabaiea and A. A. Higazy, "CdSe Nanocrystals in Novel Phosphate Glass Matrix," Physica E, Vol. 40, No. 10, May 2008, pp. 3049-3054. doi:10.1016/j.physe.2008.04.008

[20] S. Wageh, M. H. Badr, M. H. Khalil and A. S. Eid, "Strong Confinement of PbSe Nanocrystals in Phosphate Glass,” Physica E, Vol. 41, No. 7, January 2009, pp. 1157-1163. doi:10.1016/j.physe.2009.01.011

[21] A. A. Higazy, B. Bridge, A. Hussein and M. A. Ewaida, "Elastic Constants and Structure of the Vitreous System $\mathrm{ZnO}-\mathrm{P}_{2} \mathrm{O}_{5}$," Journal of Acoustical Society of America, Vol. 86, No. 4, April 1989, pp. 1453-1458. doi:10.1121/1.398705

[22] Y. M. Moustafa, K. El-Egili, “Infrared Spectra of Sodium
Phosphate Glasses,” Journal of Non-Crystal Solids, Vol. 240, No. 1-3, March 1998, pp.144-153. doi:10.1016/S0022-3093(98)00711-X

[23] A. Guinier, ““X-Ray Diffraction In crystals, Imperfect Crystals, and Amorphous Bodies,” W. H. Freeman and Company, San Francisco and London, 1963.

[24] U. E. H. Laheld and G. T. Einevoll, "Excitons in CdSe Quantum Dots,” Physical Review B, Vol. 55, No. 8, 1997, pp. 5184-5204. doi:10.1103/PhysRevB.55.5184

[25] G. Allan and C. Delerue, "Confinement Effects in PbSe Quantum Wells and Nanocrystals,” Physical Review B, Vol. 70, No. 24, December 2004, pp. 245321- 245330. doi:10.1103/PhysRevB.70.245321

[26] C. De Mello Donega and R. Koole, "Size Dependence of the Spontaneous Emission Rate and Absorption Cross Section of CdSe and CdTe Quantum Dots,” The Journal of Physical Chemistry, Vol. 113, No. 16, 2009, pp. 65116520. doi:10.1021/jp811329r

[27] Y. Wang, A. Suna, W. Maheler and R. Kasowski, "PbS in Polymers, From Molecules to Bulk Solids," Journal of Chemical Physics, Vol. 87, No. 12, December 1987, pp. 7315-7322. doi:10.1063/1.453325

[28] S. Cai, W. J. Zhang, G. H. Xu, J. Y. Li, D. M. Wang and W. Jiang, "Microstructural Characteristics And Crystallization Of $\mathrm{CaO}-\mathrm{P}_{2} \mathrm{O}_{5}-\mathrm{Na}_{2} \mathrm{O}-\mathrm{ZnO}$ Glass Ceramics Prepared By Sol-Gel Method,” Journal of Non-Crystalline Solids, Vol. 355, No. 4-5, February 2009, pp. 273-279. doi:10.1016/j.jnoncrysol.2008.11.008

[29] M. Abid, M. Et-tabirou, M. Taibi, "Structure and DC Conductivity of Lead Sodium Ultraphosphate Glasses," Materials Science and Engineering B, Vol. 97, No. 1, January 2003, pp. 20-24. doi:10.1016/S0921-5107(02)00390-2

[30] G. Le Saoüt, P. Simon, F. Fayon, A. Blinn and Y. Vaills, "Raman and Infrared Study of $(\mathrm{PbO})_{\mathrm{x}}\left(\mathrm{P}_{2} \mathrm{O}_{5}\right)_{(1-\mathrm{x})}$ Glasses," Journal of Raman Spectroscopy, Vol. 33, No. 9, September 2002, pp. 740-746.

[31] N. B. Colthup, L. H. Daly and S. E. Wiberley, "Introduction to Infrared and Raman Spectroscopy,” Third Edition. Academic Press, Inc., Massachusetts, 1990.

[32] J. O. Byun, B. H. Kim, K. S. Hong, H. J. Jung, S. W. Lee and A. A. Izneev, "Properties and Structure of RO- $\mathrm{Na}_{2} \mathrm{O}-\mathrm{Al}_{2} \mathrm{O}_{3}-\mathrm{P}_{2} \mathrm{O}_{5}$ (R = Mg, Ca, Sr, Ba) Glasses,” Journal of Non-Crystal Solids, Vol. 190, No. 3, October 1995, pp. 288-295. doi:10.1016/0022-3093(95)00280-4

[33] D. E. Corbridge, "Infrared Analysis of Phosphorous Compounds," Journal of Applied Chemistry, Vol. 6, No. 10, October 1956, pp. 456-465. doi:10.1002/jctb.5010061007

[34] C. Frausto-Reyes, J. R. Molina-Contreras, C. MedinaGutiérrez and S. Calixto, "CdTe Surface Roughness by Raman Spectroscopy Using the $830 \mathrm{~nm}$ Wavelength,” Spectrochimica Acta Part A: Molecular and Biomolecular Spectroscopy, Vol. 65, No. 1, September 2006, pp. 51-55. doi:10.1016/j.saa.2005.07.082 